\title{
Reflection on the Production of Knowledge: From Postmodernism to Pseudoscience ${ }^{1}$
}

\author{
Daud Aris Tanudirjo \\ Universitas Gadjah Mada \\ Email: daud.tanudirjo@ugm.ac.id
}

\begin{abstract}
In the last few years, the Indonesian government has impelled academics and higher education institutions as the centre of knowledge production to publish their works in reputed international journal. This policy is necessary to elevate the position of Indonesian higher education institution in the World University Rankings. In fact, such a policy will not only have impact on the status of the higher education institution but also in the course of human culture and society. This article tries to reflect on the impact of the implementation of the policy in the wider cultural context. Predictably, new knowledge will only be circulated among the elite academics and the higher education institutions will become inaccessible ivory tower for the society. On the other hand, the society will tend to consume more pseudoscientific knowledge which is more attractive and easier to understand. Ultimately this will have a significant impact on the course and quality of human culture.
\end{abstract}

Keywords: Indonesian government policy, knowledge production, postmodernism, pseudoscience, scientific work

\section{INTRODUCTION}

The last few years has witnessed the strong effort of the Indonesian Government to elevate the position of Indonesian higher education institutes in the World University Rankings. One of the requirements to attain higher university rank is to publish numerous articles in reputed international scientific journal. To encourage academics and scientists to publish their works in scientific journals, very attractive financial incentives are offered by the Government. At the same time, publication in reputed international journal has been regulated as a compulsory requirement for academic promotion. Such a policy has coerced most academics and scientists to allocate more of their time and energy to produce articles for reputed journal than any other matters. In some cases, they even try to attain it by every effort, including plagiarism. It is apparent that the policy to urge publication in international journal has been induced by the global condition. Especially in Asia, the world university rankings have instigated a "reputation race" (Luxbacher, 2013). Clearly that Indonesian Government has decided to take part in the race.

No one will deny that the high ranking will be rewarding for the university. To some extent this will also bring a sense of pride for the nation-state where the university belongs to. However, it is not quite clear yet whether such a tough and demanding competition has contributed significantly to humanity at all. Even if the university ranking is beneficial, it leaves a question as to who will actually benefit from such a competition. While admitting some benefits of the World university ranking through publications 
and citations, Hazelkorn (2009) clearly points to the problems of the ranking system which implies a single definition of quality. In fact, each university has its own vision and mission which cannot be measured in a few general indicators such as the number of publication and citations. This ranking system has made the art, humanities, social sciences, engineering, business and education vulnerable, as those disciplines "do not have a strong tradition of peer-reviewed publication". The ranking system is also caused a wider gap between elite and mass education and between universities in the developed and developing countries.

A higher education institution is a center of knowledge production and reproduction. As such the institution has surely involved in the transformations of knowledge and skills from one generation to another generation. Academics explore and exercise new knowledge in dynamic social environment. Naturally there is always growing demand for excellent performance to keep up with the need of progress. In the modern world progress has become an obsession that everyone will be ready to sacrifice anything to reach. Thus, an increase in the number of indexed publications, a large number of graduates, a high GPA, an ontime graduation, and a large number of graduates earning cumlaude citation all together seem to have become the standard indicators of success in higher learning institution. However, being totally absorbed in our efforts to reach those indicators, academics hardly ask themselves whether all those effort meaningful to the humanity. This question is deserved an answer as the knowledge production is an important part of the formation of culture. Hence, if culture is essentially a journey to make human more humane, do what academics have achieved so far really go in that direction? There should be reflection whether all that have been achieved so far have even brought us further away from the goal of culture to make us more humane.

This article addresses the possible impact of the policy to impel academics and higher education institutions to publish their works in reputed or indexed international journals. In this article the policy is perceived as a part of knowledge production system in the human culture. Therefore the implementation of the policy will consequently have significant impact in the progress of the society.

\section{FINDINGS AND DISCUSSION}

\section{Culture and Knowledge}

I am fully aware of the fact that it is not a simple attempt to make a reflection on culture. Indeed, to do a comprehensive reflection on culture requires an involvement of a vast array of thoughts and elaborate discussion, which is clearly impossible to do with a limited space we have in this journal article. In regard to this, I will try to offer only some ideas to provoke further profound thought and more elaborate discussion. Apart from that, I will give more emphasis on the elements of culture that are relevant with the assignment of higher learning institute whose core business is education and producing knowledge. In this institution, knowledge or science is produced and reproduced.

Before proceeding into the discussion, I need to explain the logic that serves as the framework of thought. It is understood that people comprehend cultural entity in many different ways. However, it is also generally acknowledged that culture encompass almost all aspects of human life. Until the past few decades, culture remained to be discussed as theories or mere application of particular theories. But today the concept of culture includes a wide variety of all human intentional practices: from manner of eating, speaking, art performance, television broadcast, urban planning, political decision, to education and learning processes.

Culture also comprises a set of policies to guide the direction of human life (Perseun, 1976; Robbins, 2009). In fact, the policies that define human's journey are made on the basis of a set of knowledge that human believes in. The relationship between knowledge or science and policy or decision making in the society has been discussed by Paul Fayerabend as well as Harry Collins and Robert Evans (Sorgner, 2015). Fayerabend is deeply concerned with the possibility that the inclusion of knowledge or science may pose hazard to the decision that the society should make in a democratic manner because the authority of knowledge will almost always construct into the most correct, correct, and less correct. On the contrary, Collins dan Evans would rather regard that democracy harms the purity of knowledge or 
science, which sometimes rejects to compromise, let alone to be democratic. Both sides, however, argue that knowledge or science will become not only cultural resources, but also the major force for the cultural dynamic. Collins and Evans even claim that knowledge or science not only serves as the cultural resources, but also becomes the main element of culture. By acquiring the knowledge, human no longer is a somatic creature; it advances into an extra somatic creature. Human think, which makes them a species endowed with an ability to make plans for his life.

Van Peursen (1976), indeed, points out the important role that knowledge plays in the development of culture. He found that the characteristic of a culture is determined by the way its members understand the phenomena surronding their body. Therefore, Van Peursen divides culture into the three stages : mythical, ontological, and functional. Basically, at the mythical stage, culture is based on the knowledge with which human perceives ves as an inevitable part of the universe. Human feels being confined under the power of the universe which puts them into submissiveness, or allows the use of his power only to adapt themself to it. In the subsequent stage, human realizes themself as a part of the universe, but he needs to take a distance in order to better understand the universe. Keeping a distance from the universe is carried out to free themselves from the power of the universe and offer a more objective answer to the question what actually exists and happens in the universe. In this stage, human always asks a question related to the nature of thing (substantialism). Finally, in the functional stage, human already gains understanding on what exists and happens in the universe and manages to identify the relation between the phenomena they have understood and their signification or usage into particular functions. This functional consciousness is often perceived as one of the characteristics of modernity. From Peursen's description of the development of culture, it becomes clear that knowledge plays a very important role in defining to which the direction a particular culture is going.

Although van Peursen views those stages as significant changes, it does not mean that man climbs up one stage after another. Each stage always has both positive and negative sides. For that, van Peursen reminds us not to be too romantic in imagining the past nor too utopic in anticipating the future (Peursen, 1976). Why is this attitude? It is because a futurologic prediction is often made by simply following what the culture has undergone, in straight lines. In fact, a culture may not always follow a straight-line transformation; sometimes it takes a winding route or even goes trajectory. Consequently, the utopia highly desired to become a reality will remain as a beautiful dream that never comes true.

A utopic failure that van Peursen has warned us apparently has happened to the modernity, which was initiated in the Age of Enlightenment a few centuries ago. The modernity is a concept developed upon rationality which is the fruit of the success in developing ontological ideas. However, it does not stop there; it goes even further into functionalism stage. Some evidences are available from its transformation which was marked by a number of knowledge discoveries that gave birth to the Industrial Revolution. It was such an impressive success that it became a part of the identity of western culture. Through the process of colonization the modernity began to build its foundation of hegemony almost around the world. The rise of globalization in an even faster growth following the World War II and Cold War has enhanced the hegemony. Human, at a particular stage, becomes spellbound and then rely their big hopes on the utopia of modernity. Many strongly believe that modernism will bring them into a better life through the technology and science as well as the engineering of social life. In the field of phylosophy of knowledge, the idea of modernism is claimed to be able to offer a thorough explanation about the existing reality. It adopts the positivism as the underlying epistemology, which gives a bigger emphasis on objective rationality by giving a special emphasis on analytical studies. This framework of thinking also tends to be dichotomic, putting everything into either black or white. Moreover, within the modern rationality, knowledge can only be acquired through the falsification method in which the deductive method is applied for gathering evidence for rejection (Popper, 2002).

Modern epistemology, in fact, has been a continuous debate and received a lot of criticisms 
from even among modernism thinkers themselves. They belong to a group of radical modernists, including Karl Marx, Emile Durkheim, Jurgen Habermas, Max Weber, Max Horkheimer, Theodore Adorno, and Luis Althusser (Crook, 1991). The debate is basically centered around the problem of how knowledge is acquired and about its legitimacy. In this context, they continue to challenge between episteme, or knowledge acquired through critical endeavour by applying a particular method, and doxa, which is a point of view or a mere opinion. In the social life, it is a crucial problem because knowledge serves also as the basis for determining many things, including justice (which is right or wrong). Does a single objective truth or knowledge really exist, as many modernists imagine? This question always becomes the target of the critical thinking both among the thinkers of Frankfurt School and among the post-structuralists in France (Crooke, 1991).

Meanwhile, even in the domain of social life, the society finds that modernism has been unable to become a vehicle to reach human welfare and welbeing. On the contrary, bearing some characteristics of individualism, materialism, and liberalism it has brought various new problems: environmental damage due to overexploitation, widening social and economic gap, degrading sense of humanity, and domination of western culture. Modernity is seen as giving advantages only to those with power, just like what has happened to the capitalistic economic system. This process eventually brings domination and authority, while eliminating heterogenity. In the field of knowledge or science, western rationality turned out to be not always effective in offering explanation for all phenomena. The knowledge acquired from the application of "objective" methodology is not always objective. The fact that subjectivity already resides in every construction of knowledge gives reasonable account for this flaw. What is claimed to be a scientific certainty (episteme) is actually a point of view containing bias (doxa). It is right from here that the discourse on the crisis of knowledge legitimacy starts. The rule of the game in the modernism's construction of science is a process of legitimacy in itself. Therefore, the modernism's construction of science is accused of being an attempt to maintain the domination of the modernism's grand narrative itself.

Denial against the rationale of modernism grew stronger, and emerged as post-modernism. This phenomenon happened almost simultaneously in many fields of life: art, architecture, physics, literature, fashion, music, and philosophy of knowledge. In the field of science, the term post modernism was introduced and made popular by Jean- Francois Lyotard when he wrote his book La Condition Postmoderne in 1979. Lyotard's idea centers around a belief that reality is a phenomenon that rationality theory is unable to represent accurately as modernism holds. $\mathrm{He}$ also questions about the legitimacy of knowledge as proposed by Habermas, and challenges the power of reason. Reasoning is not the only way to achieve an understanding on a thing; other means are possible such as sensation and emotion. Everything is treated equally as if it were able to be measured in the same way, and put into the same measurement unit, while, in fact, it cannot. The difference of one knowledge from the other owes to "language games", each follow its own rules of the game. For isnstance, different conventions apply among philosophers and among experts. For that, Lyotard gives an emphasis on critical attitude, or even scepticism toward the metanarrative which modernism has formulated. Accordingly, he opens up a new door to different views. This attitude indicates his acknowledgement and at the same time bid for heterogenity. In this context Lyotard (1984 : xxv) proposes that:

"Post-modern knowledge is not simply a tool of the authorities; its refine our sensitivy to differences and reinforce our ability to tolerate the incommensurable"

It is true that post-modernism is not only Lyotard. There are a number of different ideas from other prominent figures, especially from France, such as Jean Baudillard, Jacques Derrida, Gilles Deleuze, dan Michel Foucault (Crook, 1991; Aylesworth, 2015). As the name suggests, post-modernism is actually a continuation of modernism. The difference lies in the fact that it is successful in sharpening the criticism addressed by radical modernist group, especially Althuser. However, it is impossible to discuss here all the ideas from those thinkers. This paper will offer only a general 
description of the post-modernism condition.

\section{Post-modernism}

As a reaction to modernism, post modernism tends to be critical and deconstructive in nature. Almost all ideas it has developed contradict modernism idea. The basic assumption of postmodernism is that knowledge is a subjective, never objective, entity. Everyone does not necessarily have uniform perception even to something they believe as a "fact". It means that the meaning of "fact" will depend on who defines it (relativism). As a result, "truth" is also relative. The legitimacy of knowledge is highly dependent on its own context, and is reflective in nature. Therefore, post-modernism rejects a normative, deterministic way of thinking as well as an assumption on the existence of a single truth as the positivism holds. On the contrary, post modernism attempts to accommodate various thought having broad spectrum (multi-dicipline, trans-dicipline) and regards any truth as pluralistic. This also includes other alternative points of view such as feminism, the indigenous, and the unrepresented. In this way, they hope to enable representation for various voices that are, in fact, present (multivocal). All these characteristics, of course, help to build an image that post modernism is a more democratic and cultured figure (summarized from many sources, see among others Aylesworth, 2015; Lyotard, 1984; Friedman, 1994; Faucoult, 1972; Nikkel, nd ; Hodder, 1991).

In a more critical manner, Sokal (2004) points out that post-modernism is an explicit rejection toward the rationality of the Age of Enlightenment, by means of a theoretical discourse or not in the domain of empirical data verification but rather based on the assumption on the relativism of culture and knowledge. Therefore, they do not distinguish knowledge and science from naration, myth, or other social constructions. "Truth" depends on a social group, being judged more as a moral or ethic rather than on the available empirical data or knowledge. Further, Sokal gives some examples of postmodernism ideas that reflect this value, among others is one that knowledge/ science has no relationship with the natural fact; natural world does not, or hardly plays a role in creating knowledge; or in fact, no standard of quality exists to determine what is being rational, since what can be found is only local rationality. Post-modernism sees science legitimizing itself by relating its discoveries with a particular authority. Such relationship determines whether or not a science is valid.

\section{Pseudoscience}

Amid the offers from post-modernism which open up wide opportunities for relativism, multivocality, pluralism, multi- and trans-dicipline approaches, knowledge based on the so-called pseudoscience have developed very fast. The term pseudoscience was first introduced by historian James Andrews in 1796 to refer to alchemy ${ }^{2}$ as a fantastic pseudoscience. This term has been frequently used since the turn of 19th century, but gradually earns a more negative sense. Nevertheless, the boundary between science and pseudoscience is quite thin (Sokal, 2004; Raff, 2013; Hansson, 2014; Beyerstein, 1996). In fact, a demarcation is recognized in the domain of knowledge or science (Hansson, 2014) that distinguishes nonscience, such as religion and metaphysics, from unscientific which does not follow, or deviate the scientific principles. Pseudoscience is a minor part of the unscientific. In general, pseudo-science always gives a false impression that it has some basic reasoning which is in compliance with the logical reasoning of knowledge or science in general. Pseudoscience also tends to foreground a sophisticated and accurate methodology, and dwells under the authority of a particular science. In lieu of authority, pseudoscience often claims long lost wisdom from the past as the source of its discoveries. The advocates of pseudoscience usually consider themselves as if they had deconstructed old theory, and their new discoveries were able to solve various problems or to reveal the unknown mistery.

Behind the grandeur impression of its discoveries, pseudo-science hides a number of weaknesses, which are, among others: not being supported with adequately strong data, using the data inappropriately, or interpreting the data using their own framework of thinking. Pseudoscience usually fails to be predictive, its claims are difficult to get confirmation, and it is ignorant to comments on its weaknesses. Although it believes to have 
changed old knowledge, pseudo-science is seldom able to explain why old knowledge is incorrect and needs replacement. It ignores the fact that old knowledge has been supported with a large body of data which are accumulated during a long period of time. Apart from that, its new discoveries are sometimes driven by unscientific motives, be it ideological, political, or financial ones. Instead of targetting criticism against themselves, pseudoscience advocates will put themselves as a victim of repression from an established authority. They are suffering from Galileo syndrome, i.e., to feel being condemned, isolated, and punished for standing against the mainstream of science. Regardless of this, they are optimistic that their opinion will win approvals one day.

For the pseudoscience advocates, the emergence of post-modernism is taken as a golden opportunity. Taking the position of an opressed producer of alternative ideas, they now find access to a larger room of representation. The success of post-modernism seems to drag pseudoscience into an almost equal position among other sciences in general. Pseudoscience advocates often use post-modernism ideas to justify their own ideas, while the post-modernism thinking framework is, in fact, totally different from that of pseudoscience. Sokal (2004) even strongly argues that "Pseudoscience is not postmodernism". $\mathrm{He}$ asserts that pseudoscience always claim that the acquired knowledge is objective which in fact are contradicts to the post-modernism's denial against objective knowledge. Another difference is that post-modernism insists on constantly critical thinking that pseudoscience overlooks. It may be true that post-modernism has neither borne nor promoted pseudoscience, but it has weakened the moral principle and epistemology of the proper science. Thus, post-modernism has undeniably contributed to the development of pseudoscience. Moreover, with its multivocal mission, postmodernism admits that pseudoscience deserves a voice. Borrowing Bertrand Russel's words, Sokal (2004) says that postmodernism "has created a sea of craziness which is hazardous to a small boat of man's rationality".

Then, why the rise of pseudoscience becomes a concern to us? Why don't we let them be just like other voices, in order to reach the ambition of democracy? Presumably we agree that we must make a great effort for democracy, equality, and emphaty to "the other". However, the spirit of pseudoscience is not purely pursuing a new better science in a way similar to Lyotard's (1984) postmodernism discourse. Unlike post-modernism that aims at preserving diversity, pseudosaince will one day become a new hegemony in the discourse of knowledge. This will eventually dismiss the ambition of democracy and equality. Moreover, it is now become evident that the increasing number of pseudoscience knowledge has infiltrated our social life by means of consumtive advertisements, alternative medicine, professional witness in trials, environmental policies, racism, religious fundamentalism, and of course, deviation in the learning of science itself. We must realize that pseudoscience today has the capability to be involved in the decision making process that produces policy that is crucial to determine the course of our culture in the future (Sokal, 2004; Hansson, 2014; Raff, 2013). In Indonesia, we have observed how pseudoscience has influenced the government policy regarding at least the case of blue energy (water conversion into fuel), and the claim that Gunung Padang site is the oldest pyramid in the world containing thousands kilograms of precious metal.

Therefore, there is a great probability that the development of our culture will be guided by pseudoscience. If the situation proceeds the direction of our culture will be led by new myths which are never brought open into a more dialectical discourse. It is seriously questionable if pseudoscience knowledge will bring our culture into becoming an instrument to make ourselves more humane.

In such a situational context described above, then the actual reflective question address in the introductory part of this paper finds its relevance. We must openly answer whether or not the policy to take part in the "reputation race" through the world university rankings will brings us closer to our goal to make human more humane? This paper is not in the position to give direct answer to the question. However, there is good reason to worry that the policy of higher education in Indonesia is drifted away by the strong current of globalization such that it diverts its course away from the 
originally intended goal.

It is stated in the 1945 Constitution of the Republic of Indonesia that the government is given a mandate for educating the people of Indonesia. This mandate is stipulated in the the Laws on the National Education System, with the aim to educate the students to be a man of belief and submission to God the Almighty, having good moral conduct, healthy, learned, witty, creative, independent, and both democratic and responsible citizen. In fact, the Indonesian higher education policy at present strongly encourages universities to earn the prestige of world ranking. So much resource and energy are exploited to reach this obsession. The university performance is even now measured based on the world ranking. Here we can see that our education policy makers have been constructed by new myths of pseudoscience on the success of education. There are reasons for this statement. Firstly, like in pseudoscience, the proposition that universities with top ranking have a better performance than those with lower ranking cannot be falsified. On the contrary, the truth of this proposition cannot be empirically proven. Consequently, using world ranking as the standard of university performance is a pseudoscience which cannot be legitimized. Secondly, we forget what Lyotard has proposed that the validity of knowledge should be determined by local legitimacy. It means that if the goal of our education is to educate the people of Indonesia, using the world ranking as the standard measure is not relevant. A more appropriate standard to measure the achievement of our education goal will be the Indonesian local condition. For that, we ourselves need to develop our own standard, not simply borrow from others.

If we do not want to be trapped into referring to pseudoscience myths as mentioned above the government should have made confirmation: do top world ranking universities really show excellent performance in educating the people of Indonesia? Many universities are so busy with targetting high ranking that they forget the main goal of educating the people. Similar situation can happen when higher education institute performance is measured by the number of graduates achieving cum laude citation or earning high grade point average (GPA). Many higher education institutes are driven to give their students high grades in order to show their high-level performance. They forget the purpose of the standard as a measure of learning output quality. As a result, university may show excellent performance but produces low quality learning output.

Another policy which also potentially develops pseudoscience is disbursement of incentive for writer who publishes an article in accredited, or internationally indexed journals, particularly Scopus, in regards to increasing the number of publication. All universities seem to vie to get as many academic works of their faculty members as possible published in those journals. Consequently, new scientific discoveries and knowledge are known only by their peers. All are circulating around, or inside the ivory tower. It can almost be taken for granted that a wider circle of society will have no access to those new scientific discoveries. The society will, in turn, absorb more knowledge of pseudoscience. It is in line with Sokal's opinion (2004) that the society think "doing real science is difficult". Therefore, they prefer to consume ideas or knowledge that are easy for their comprehension, appear to be scientific, and are understood as revolutionary new discoveries. All of these are available from pseudoscience. As a result, more decisions are made according to pseudoscience knowledge than based on scientific researches. To prevent this phenomenon from becoming rampant, academics should consider publishing their works not only in academic journals but also in scientificpopular publications, which will give bigger contribution to the people education. At the same time, it is necessary to help reduce the possibility for pseudoscience knowledge to become the basic consideration which direct our culture to the future.

Finally, according to Lyotard (Frederick, 1984), in the condition of post-modernism the scientific work is not to produce a stable model of knowledge or to redescribe reality out there, but simply to add more works to do, or to produce more new scientific knowledge, and to ensure that new ideas will always be created. This should become the ethos that driving academics and scientists. With overwhelm financial incentive offered by the government there is always a risk for scholars to produce only knowledge that boost their financial gain. This will certainly make the 
process of knowledge production imbalance.

\section{CONCLUSION}

From the above discussion it is apparent that the policy to impel academics and scientists to publish mainly their works in reputed international journal will potentially have a significant impact in the development of our culture in the future. It will result in the wider gap between the elite scholar knowledge and that of the general public. It will also cause imbalance in pursue of general knowledge as scholars are driven to do more knowledge production from which greater financial benefit will be obtained. Ultimately, the policy raises the potential of the development of pseudoscientific which may lead our culture back to the mythical stage.

It is worthwhile to recall for the story of the genious scholar, Isaac Newton. His great gravity theory written in Principia was once submitted to the physicists at Cambridge University posthumously. His writing was rejected and all the documents were sent back to his family. The documents sat for long in the family barn until around 1930s the family finally sold the documents to the bric-and-brac shop. After the World War II the document appeared in an antique book shop. From that antique book shop did the scientists recognize Newton's genious discovery. They started to analyze the content of the documents and rewrite it into a monumental work in the field of physics. Noam Chomsky (2011) says that a similar story also happens to many other scientists having extraordinary ideas. Their works are not found in reputable journals, but discovered among the society. The intended moral of the story is that producing works in the domain of knowledge or science cannot be isolated from the condition of the social and cultural situation in the society.

\section{REFERENCES}

Aylesworth, G. (2015). Post-modernism, Stanford Encyclopedia of Philosophy, the latest revised version 5 February 2015. (http://plato.stanford. edu/index.html).

Beyerstein, B.L. (1996). Distingushing Science to Pseudoscience. An article prepared for the Centre for Curriculum and Professional Development Victoria Canada.
Chomsky, N. (2011). How the World Works. Hamish Hamilton.

Crook, S. (1991). Modernist Radicalism and Its Aftermath. Routledge.

Faucoult, M. (1972). The Archaeology of Knowledge. Tavistock Publisher.

Frederick, J. (1984). Foreword, in Lyotard, J.F. The Postmodern Condition: A Report on Knowledge. Manchester University Press, p. vii - xxi

Hansson, S.O. (2014). Science and Pseudo-science. Stanford Centre for the Study of Language and information.

Hazelkorn, E. (2009). The problem with university rankings.

(http://SciDevNet/global/education/opinion/ the problem-with-university-ranking. 11 $\mathrm{March} \quad 20000$ ).

Hodder, I. (1991). Post-modernism, post-structuralism, and post-processual archaeology, in Ian Hodder (ed.) The Meaning of things. London: Harper Collins.

Luxbacher, G. (2013). World university rankings: how much influence do they really have? The Guardian, 10 September 2013 (http://amp. theguardian.com 10 September 2013)

Lyotard, J-F. (1984). The Postmodern Condition: A Report on Knowledge. Manchester University Press. Translated from French by Geoff Bennington and Brian Massumi.

Nikkel, D. (nd). Discerning the Spirits of Modernity and Postmodernity, Tradition \& Discovery: The Polanyi Society Periodical, 33:1, 8- 26.

Peursen, C.A. (1976). Strategi Kebudayaan. Penerbit Kanisius - BPK Gunung Mulia.

Popper, K. (2002). The Logic of Scientific Discovery. Routledge Classic.

Raff, J. (2013). What's the difference between science and pseudo-science? Violence Metaphores. (http://violentmetaphors.com/2013/05/17/ whats-the-difference-between-science-andpseudo-science).

Robbins, R.H. (2009). Cultural Anthropology: A problem-based approach. Cengage Advantage Books.

Sokal, A.D. (2004). Pseudo-science and Postmodernisme: Antagonist or Fellow Travelers? in G. Fagan (ed.), Archaeology Fantasies: How Pseudo-archaeology Misrepresents the Past and Mislead the Public Routledge. 
Sorgner, H. (2015). Challenging expertise: Paul Feyerabend vs. Harry Collins \& Robert Evans on scientific authority and public participation, Studies in History and Philosophy of Science, xxx (2015), p. $1-7$.

\section{(ENDNOTES)}

1 This article is written based on the academic oration delivered by the authors before the Senate of the Faculty of Cultural Science, Universitas Gadjah Mada, in the $70^{\text {Th }}$ Anniversary of the Faculty on 3 March 2016.

2 Alchemy is "chemistry" in the Middle Age which was believed to be able to purify and improve any kinds of metal into precious gold. 